\title{
The alveolar-capillary membrane diffusing capacity and the pulmonary capillary blood volume in heart transplant candidates
}

\author{
O A Al-Rawas, R Carter, R D Stevenson, S K Naik, D J Wheatley
}

\begin{abstract}
Objectives-To determine the mechanism of impairment of pulmonary transfer factor for carbon monoxide $\left(\mathrm{TL}_{\mathrm{CO}}\right)$ in heart transplant candidates, as this is the most common lung function abnormality.

Setting-Regional cardiopulmonary transplant centre.

Methods- $\mathrm{TL}_{\mathrm{CO}}$ and its components (the diffusing capacity of the alveolar-capillary membrane $\left(\mathrm{D}_{\mathrm{M}}\right)$ and the pulmonary capillary blood volume $\left(\mathrm{V}_{\mathrm{C}}\right)$ ) were measured using the Roughton and Forster method and the single breath technique in 38 patients with severe chronic heart failure awaiting heart transplantation (mean age 51 years, range 19 to 61 ; mean left ventricular ejection fraction $12.8 \%$ ). Results were compared with data from 26 normal subjects (mean age 47 years, range 27 to 62 ).

Results-Mean per cent predicted $\mathrm{TL}_{\mathrm{CO}}, \mathrm{D}_{\mathrm{M}}$, and $\mathrm{V}_{\mathrm{C}}$ were significantly reduced in patients $(69.9 \%, 81.4 \%$, and $80.2 \%$ of predicted, respectively) compared with controls $(97.7 \%, 100.1 \%$, and $102.3 \%$ of predicted, respectively, $\mathrm{p}<0.001$ ). The relative contribution of the two components of $\mathrm{TL}_{\mathrm{CO}}$ in patients was similar to that of normal subjects, with each component accounting for approximately $50 \%$ of the total resistance to diffusion $\left(1 / \mathrm{TL}_{\mathrm{CO}}\right)$.

Conclusions- $\mathrm{TL}_{\mathrm{CO}}$ impairment in patients with severe chronic heart failure awaiting heart transplantation results from a proportionate reduction in both $\mathrm{D}_{\mathrm{M}}$ and $\mathrm{V}_{\mathrm{C}}$, suggesting a significant disturbance of the pulmonary vascular bed.

(Heart 2000;83:156-160)
\end{abstract}

Keywords: heart failure; diffusing capacity; pulmonary transfer factor; pulmonary capillary blood volume

Heart failure is associated with a variety of pulmonary function abnormalities including reduced lung volumes, airway obstruction, and reduced pulmonary transfer factor for carbon monoxide $\left(\mathrm{TL}_{\mathrm{CO}}\right) .{ }^{1}{ }^{2}$ Studies in patients who are not candidates for heart transplantation (that is, those with less severe heart failure) have shown that $\mathrm{TL}_{\mathrm{CO}}$ is usually normal or only slightly reduced even during episodes of acute heart failure. ${ }^{13-5}$ It was suggested that the increased pulmonary capillary blood volume in acute congestive heart failure probably compensates for the effects of pulmonary oedema which would be expected to reduce $\mathrm{TL}_{\mathrm{CO}}{ }^{1}$ Puri and associates ${ }^{6}$ provided the first report on the changes of $\mathrm{TL}_{\mathrm{CO}}$ and its components in stable patients with mild to moderately severe chronic heart failure (New York Heart Association (NYHA) functional classes II and III). In the entire group (38 patients), mean $\mathrm{TL}_{\mathrm{CO}}$ was reduced compared with controls and this was primarily due to a reduction in the diffusing capacity of the alveolar-capillary membrane $\left(D_{M}\right) . T L_{C O}$ and $D_{M}$ were both lower in patients in NYHA functional class III than in those in class II. In contrast, there was no significant difference in mean pulmonary capillary blood volume $\left(\mathrm{V}_{\mathrm{C}}\right)$ between NYHA class II patients and normal controls, though $\mathrm{V}_{\mathrm{C}}$ was greater in class III patients than in the controls. It was suggested that $\mathrm{D}_{M}$ might be a useful marker for the alveolar-capillary membrane damage caused by pulmonary hypertension.
In patients with severe chronic congestive heart failure awaiting heart transplantation, $\mathrm{TL}_{\mathrm{CO}}$ impairment is more frequent. ${ }^{7-12}$ However, the $\mathrm{TL}_{\mathrm{CO}}$ components $\mathrm{D}_{\mathrm{M}}$ and $\mathrm{V}_{\mathrm{C}}$ have not been determined in these patients.

Our aim in this study was to determine the mechanism of $\mathrm{TL}_{\mathrm{CO}}$ impairment in patients with severe chronic heart failure awaiting heart transplantation in terms of the relative contribution of each of its components.

\section{Methods}

STUDY POPULATION

$\mathrm{TL}_{\mathrm{CO}}$ and its components were determined in 38 patients with severe chronic heart failure awaiting heart transplantation (candidates) and 26 normal subjects recruited as volunteers from the general population, in whom there was no evidence of cardiopulmonary disease. All heart transplant candidates were stable at the time of assessment. Antifailure treatment consisted of diuretics (all patients), angiotensin converting enzyme inhibitors (30 patients), digoxin (19 patients), and other vasodilators (13 patients). The exclusion criteria of the study were: current smoking or smoking cessation for less than one year before assessment; treatment with amiodarone or $\beta$ blockers; history of primary lung disease; and abnormal spirometric or lung volume results.

LUNG FUNCTION TESTS

Spirometry and lung volumes

Standard spirometry and lung volumes were measured using a body plethysmograph. 
Measured variables included vital capacity (VC), forced vital capacity (FVC), forced expiratory volume in one second $\left(\mathrm{FEV}_{1}\right)$, and total lung capacity (TLC). Predicted normal values were determined using the European Community for Steel and Coal equations for all variables. ${ }^{13}$ The lower limit of normality for each variables was defined as the predicted value minus 1.64 standard deviations of the reference regression equation according to the guideline of the European Respiratory Society. ${ }^{13}$

\section{$T L_{C O}$ and its components}

Roughton and Forster showed that the measurement of $\mathrm{TL}_{\mathrm{CO}}$ at different alveolar oxygen tensions allows the estimation of the diffusing capacity of the alveolar-capillary membrane $\left(D_{M}\right)$ and the instantaneous pulmonary capillary blood volume available for gas transfer $\left(\mathrm{V}_{\mathrm{C}}\right) \cdot{ }^{14}$ According to Roughton and Forster, the relation between $\mathrm{TL}_{\mathrm{CO}}$ and its components is described by the following equation:

$$
1 / \mathrm{TL}_{\mathrm{CO}}=1 / \mathrm{D}_{\mathrm{M}}+1 / \theta \mathrm{V}_{\mathrm{C}}
$$

where $1 / \mathrm{TL}_{\mathrm{CO}}$ is reciprocal of the transfer factor for the entire lung and represents the total resistance of the lung to CO transfer. By analogy, $1 / D_{M}$ represents the resistance of the alveolar-capillary membrane and $1 / \theta \mathrm{V}_{\mathrm{C}}$ represents the resistance of the total mass of erythrocytes in the capillary blood (intracapillary resistance). Theta $(\theta)$ is the standard rate at which $1 \mathrm{ml}$ of whole blood takes up $\mathrm{CO}$ and this is dependent on the prevailing alveolar oxygen tension and haemoglobin concentration. In the conventional calculation of $\mathrm{TL}_{\mathrm{CO}}$, haemoglobin concentration is assumed to be normal $(146 \mathrm{~g} / \mathrm{l}) .{ }^{15}$ The effect of haemoglobin on $\mathrm{TL}_{\mathrm{CO}}$ values can be determined using a modified version of the classic Roughton and Forster equation described by Cotes ${ }^{16}$ and recommended by both the European Respiratory Society and the American Thoracic Society ${ }^{15}{ }^{17}$ :

$$
1 / \mathrm{TL}_{\mathrm{CO}}=1 / \mathrm{D}_{\mathrm{M}}+1 /\left([\mathrm{Hb}] \times \theta \mathrm{V}_{\mathrm{C}}\right)
$$

where $[\mathrm{Hb}]$ is the haemoglobin concentration as a fraction of normal (that is, actual haemoglobin divided by 14.6). Thus the application of the Roughton and Forster model permits the determination of the relative contribution of $\mathrm{DM}, \mathrm{V}_{\mathrm{C}}$, and blood haemoglobin to $\mathrm{TL}_{\mathrm{CO}}$ changes.

The steps and details of estimating $\mathrm{TL}_{\mathrm{CO}}$ and its components $\left(D_{M}\right.$ and $\left.V_{C}\right)$ were identical to a protocol we have previously validated. ${ }^{18}$ In brief, $\mathrm{TL}_{\mathrm{CO}}$ was measured using the single breath method (Transflow; PK Morgan, Rainham, Kent, UK) according to the recommendations of the European Respiratory Society (ERS). ${ }^{15}$ The standard oxygen gas consisted of CO $(0.28 \%)$, helium $(\mathrm{He})(14 \%), \mathrm{O}_{2}(18 \%)$ with the remainder nitrogen whereas high oxygen gas mixture consisted of $\mathrm{CO}(0.28 \%)$, He $(14 \%)$ with the remainder $\mathrm{O}_{2}(85.72 \%)$. The sequence of measurements was in the following order: $\mathrm{TL}_{\mathrm{CO}}$ at standard oxygen concentration was measured first and the mean of two technically acceptable $\mathrm{TL}_{\mathrm{CO}}$ values was re- ported as the subject's $\mathrm{TL}_{\mathrm{CO}}$. The subject was then allowed five minutes breathing room air followed by another five minutes breathing pure oxygen while wearing a nose clip. The single breath $\mathrm{TL}_{\mathrm{CO}}$ at high oxygen concentration was then measured using the same steps of standard $\mathrm{TL}_{\mathrm{CO}}$ measurement, except for the use of the high oxygen mixture in the inspired gas mixture. The steps of room air breathing and pure oxygen breathing were repeated, a second high oxygen $\mathrm{TL}_{\mathrm{CO}}$ measurement was made, and the mean of two technically acceptable values was reported as the subject's $\mathrm{TL}_{\mathrm{CO}}$ at high oxygen concentration. The interval between the sets of standard and high oxygen measurements and between each of the high oxygen measurements was 10 minutes.

The values of $\mathrm{TL}_{\mathrm{CO}}$ at standard and high oxygen concentrations, with their corresponding $\theta$ values were used to determine $D_{M}$ and $V_{C}$ by solving the Roughton and Forster equation graphically (fig 1); the intersect of the plotted line $(\mathrm{AB})$ with $1 / \mathrm{TL}_{\mathrm{CO}}$ equals $1 / \mathrm{D}_{\mathrm{M}}$, and its slope $(B C / A B)$ equals $1 / V_{C}$. The values of $\theta$ were derived from the original data of Roughton and Forster obtained from in vitro $\mathrm{CO}$ uptake in a suspension of human erythrocytes at $37^{\circ} \mathrm{C} .{ }^{14}$ The effect of haemoglobin variability on $\mathrm{TL}_{\mathrm{CO}}$ values was determined using the modified Roughton and Forster equation as described by Cotes (equation 2). ${ }^{16}$ Haemoglobin concentration in patients was determined on the same day of $\mathrm{TL}_{\mathrm{CO}}$ measurement using venous blood samples. Normal subjects were assumed to have normal haemoglobin concentration (that is, $146 \mathrm{~g} / \mathrm{l}$ ). ${ }^{15}$

\section{DATA PRESENTATION AND ANALYSIS}

$\mathrm{TL}_{\mathrm{CO}}$ and its components were expressed as percentages of predicted using the European Community for Steel and Coal equations for $\mathrm{TL}_{\mathrm{CO}}{ }^{15}$ and the reference values of Cotes for $\mathrm{D}_{\mathrm{M}}$ and $\mathrm{V}_{\mathrm{C}} \cdot{ }^{19}$ The total resistance to $\mathrm{CO}$ transfer $\left(1 / \mathrm{TL}_{\mathrm{CO}}\right)$ and its components $\left(1 / \mathrm{D}_{\mathrm{M}}\right.$ and $\left.1 / \theta \mathrm{V}_{\mathrm{C}}\right)$ were expressed in absolute values $\left(\mathrm{Pa} \cdot \mathrm{min}^{-1} \cdot \mathrm{mmol}^{-1}\right)$. Unless stated otherwise, values were presented as mean with standard error of the mean (SEM). Comparisons between the two groups (heart transplant candidates and normal controls) and between the

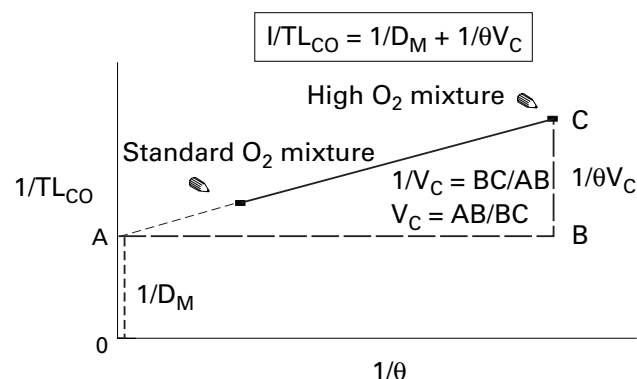

Figure 1 The graphical derivation of $T L_{C O}$ components $\left(D_{M}\right.$ and $\left.V_{C}\right)$ using the Roughton and Forster equation: $a$ plot of $1 / T L_{C O}$ against $1 / \theta$ yields a straight line which intersects the ordinate $1 / T L_{C O}$ at point $A$. At this point, the value of $1 / \theta$ equals zero and therefore the value of $1 / T L_{C O}$ at point $A$ equals $1 / D_{M}$. The triangular area above the intersection represents a plot of $1 / \theta V_{C}$ against $1 / \theta$. $V_{C}$ can therefore be obtained by dividing $1 / \theta V_{C}$ by $1 / \theta$ (that is, $\left.1 / V_{C}=B C / A B\right)$, which is the slope of the line $A C$. 
Table 1 Clinical characteristics of heart transplant candidates compared with normal controls

\begin{tabular}{lll}
\hline & Candidates & Normal \\
\hline Number of subjects & 38 & 26 \\
Age; mean in years (range) & $50.6(34$ to 61$)$ & $47.3(27$ to 62$)$ \\
Sex & $30(79 \%)$ & $20(77 \%)$ \\
$\quad$ Male & $8(21 \%)$ & $6(23 \%)$ \\
$\quad$ Female & $10(26 \%)$ & $21(81 \%)$ \\
Smoking status & $28(74 \%)$ & $5(19 \%)$ \\
$\quad$ Non-smokers & $25(66 \%)$ & \\
Ex-smokers (for more than one year) & $10(26 \%)$ & \\
Diagnosis & $3(8 \%)$ & \\
$\quad$ Ischaemic heart disease & $140(119$ to 173$)$ & \\
Dilated cardiomyopathy & $12.8(6 \%$ to $26 \%)$ & \\
$\quad$ Valvar heart disease & $91.6(2.3)$ & $102.9(2.1)^{\star}$ \\
Haemoglobin (g/l) (mean (range)) & $90.1(2.2)$ & $98.6(1.8)^{\star}$ \\
LVEF (mean (range)) & $93.1(1.4)$ & $100.2(3.3)^{\star}$ \\
Lung function (mean \% predicted (SEM)) & $91.4(1.9)$ & \\
$\quad$ FVC & FEV & \\
FEV & TLVC &
\end{tabular}

${ }^{\star}$ Denotes significant difference between the two groups; $\mathrm{p}<0.05$.

$\mathrm{LVEF}$, left ventricular ejection fraction; FVC, forced vital capacity; $\mathrm{FEV}_{1}$, forced expiratory volume in the first second; TLC, total lung capacity.

subgroups of heart candidates (non-smokers and ex-smokers) were performed using the non-paired samples Student $t$ test. Comparison between $\mathrm{TL}_{\mathrm{CO}}$ results before and after correction for haemoglobin in heart transplant candidates was performed using the paired samples Student $t$ test.

\section{Results}

SUBJECTS' CHARACTERISTICS

Table 1 shows the clinical characteristics of the study groups, including lung function results. Both heart transplant candidates and normal controls had similar age and sex distribution, but they had different smoking status with significantly more ex-smokers among candidates. Because of the selection criteria, the duration between smoking cessation and assessment was at least one year in all ex-smokers (mean 3.6, range 1 to 24 years). All heart transplant candidates had severe chronic heart failure (mean left ventricular ejection fraction 12.8 , range $6 \%$ to $26 \%$ ). Although lung function variables (FVC, $\mathrm{FEV}_{1}, \mathrm{FEV}_{1} / \mathrm{FVC}$, and TLC) were within normal limits for all subjects (a selection criterion), the mean values were slightly reduced in heart transplant candidates compared with normal controls $(\mathrm{p}<0.05)$.

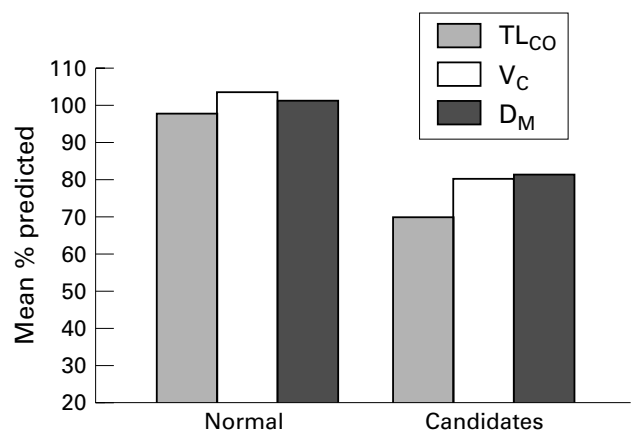

Figure 2 Pulmonary transfer factor for carbon monoxide $\left(T L_{C O}\right)$ and its components in heart transplant candidates compared with normal controls.

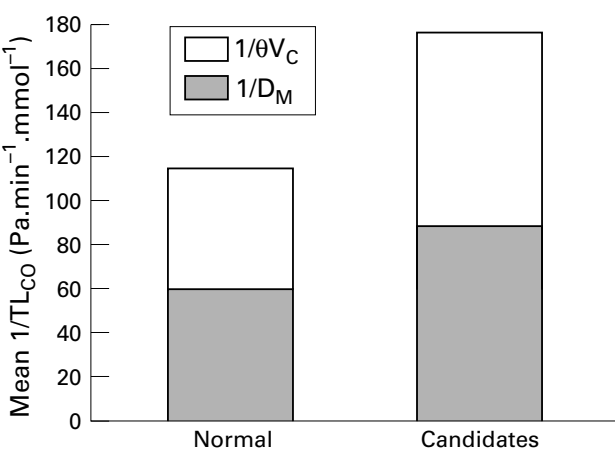

Figure 3 The total resistance to CO transfer $\left(1 / T L_{C O}\right)$ and its components $\left(1 / D_{M}\right.$ and $\left.1 / \theta V_{c}\right)$ in heart transplant candidates compared with normal controls

TL $_{\text {CO }}$ AND ITS COMPONENTS IN HEART TRANSPLANT CANDIDATES COMPARED WITH NORMAL CONTROLS

Figure 2 shows $\mathrm{TL}_{\mathrm{CO}}$ and its components in heart transplant candidates compared with normal controls. Mean $\mathrm{TL}_{\mathrm{CO}}$ was significantly reduced in the heart transplant candidates (69.9 (2.0)\% and 97.7 (1.6)\% of predicted in candidates and controls, respectively, $\mathrm{p}<0.001)$. Similarly, $\mathrm{D}_{\mathrm{M}}$ and $\mathrm{V}_{\mathrm{C}}$ were significantly reduced in candidates $(80.2$ (4.2)\% and $81.4(5.4) \%$ of predicted, respectively) compared with controls (100.0 (1.3)\% and 102 (1.1)\% of predicted, respectively; p < 0.001).

Figure 3 displays the diffusion parameters in terms of their reciprocals (that is, resistance to diffusion) in the two study groups. Mean (SEM) total resistance to CO transfer $\left(1 / \mathrm{TL}_{\mathrm{CO}}\right)$ was higher in heart transplant candidates than in normal controls (176.1 (8.6) $v$ (113.9 (3.8) Pa.min $\left.{ }^{-1} \cdot \mathrm{mmol}^{-1}, \mathrm{p}<0.001\right)$. The increase in $1 / \mathrm{TL}_{\mathrm{CO}}$ in heart transplant candidates was due to a proportionate increase in both the alveolar-capillary membrane resistance $\left(1 / \mathrm{D}_{\mathrm{M}}\right)$ and the intracapillary resistance $\left(1 / \theta \mathrm{V}_{\mathrm{C}}\right)$, being 88.4 (6.3) and 87.7 (5.0) Pa.min ${ }^{-1} \cdot \mathrm{mmol}^{-1}$, respectively, compared with 59.0 (1.0) and 54.9 (3.8) Pa.min ${ }^{-1} \cdot \mathrm{mmol}^{-1}$, in normal subjects. $1 / \mathrm{D}_{\mathrm{M}}$ and $1 / \theta \mathrm{V}_{\mathrm{C}}$ contributed equally to $1 / \mathrm{TL}_{\mathrm{CO}}$ (approximately 50\% each) in both normal subjects and heart transplant candidates.

Figure 4 shows scatter plots of per cent predicted $\mathrm{TL}_{\mathrm{CO}}$ against haemoglobin concentration in heart transplant candidates. Mean haemoglobin concentration in candidates was $140 \mathrm{~g} / \mathrm{l}$, and there was no correlation between per cent predicted $\mathrm{TL}_{\mathrm{CO}}$ and haemoglobin

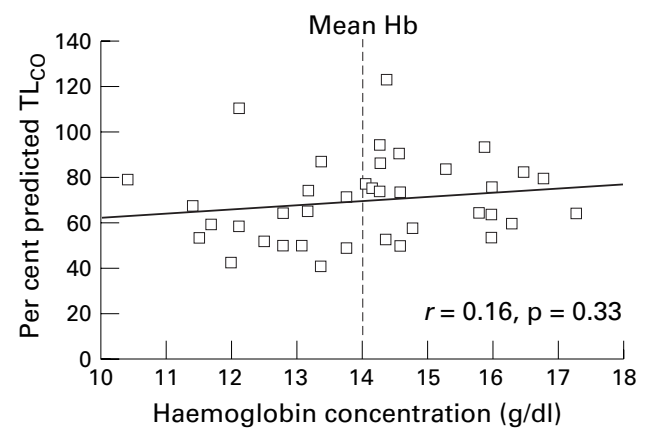

Figure 4 Scatter plots of per cent predicted pulmonary transfer factor for carbon monoxide $\left(T L_{C O}\right)$ against haemoglobin concentration in heart transplant candidates. 


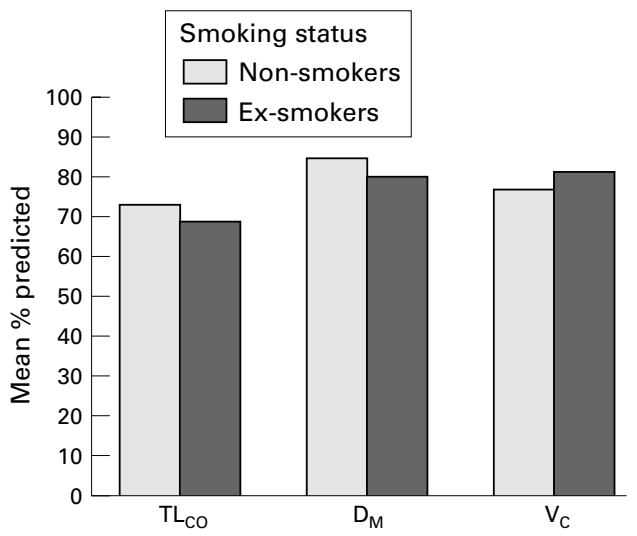

Figure 5 Pulmonary transfer factor for carbon monoxide $\left(T L_{C}\right)$ and its components in heart transplant candidates subdivided in non-smokers (10 patients) and ex-smokers (28 patients). Differences between non-smokers and ex-smokers were not significant.

concentration in candidates $(r=0.16$, $\mathrm{p}=0.33$ ). Correction for haemoglobin in heart transplant candidates produced no significant effect $(69.9$ (3.0)\% $v 71.1$ (3.1)\% of predicted, $\mathrm{p}=0.09)$.

The potential influence of previous history of smoking on $\mathrm{TL}_{\mathrm{CO}}$ and its components was assessed by dividing heart transplant candidates into two subgroups (non-smokers and ex-smokers). Figure 5 shows that there was no significant difference between the two subgroups in any of the diffusion parameters (mean $\mathrm{TL}_{\mathrm{CO}}, \mathrm{D}_{\mathrm{M}}$, and $\mathrm{V}_{\mathrm{C}}$ values were, respectively, $72.1(4.1) \%, 83.7(8.7) \%$, and 78.5 (5.3) $\%$ in non-smokers and $69.2(3.8) \%, 80.7$ $(8.0) \%$, and $80.2(5.4) \%$ in ex-smokers (per cent of predicted)).

\section{Discussion}

$\mathrm{TL}_{\mathrm{CO}}$ AND ITS COMPONENTS IN HEART TRANSPLANT CANDIDATES

The results of this study represent the first report on the changes in $\mathrm{TL}_{\mathrm{CO}}$ components in heart transplant candidates. In addition to confirming $\mathrm{TL}_{\mathrm{CO}}$ impairment in these patients, it was shown that this impairment was due to a proportionate reduction in both of its components $\left(D_{M}\right.$ and $\left.V_{C}\right)$. The lack of any effect for haemoglobin concentrations on $\mathrm{TL}_{\mathrm{CO}}$ values is a reflection of their relatively normal haemoglobin concentration. ${ }^{16}$

In the only study of $\mathrm{TL}_{\mathrm{CO}}$ components in patients with chronic congestive heart failure, Puri and associates ${ }^{6}$ reported that impairment of $\mathrm{TL}_{\mathrm{CO}}$ was common in patients with chronic heart failure and was primarily caused by a reduction in $\mathrm{D}_{M}, \mathrm{~V}_{\mathrm{C}}$ being normal. The apparent discrepancy between those results and ours probably reflects the difference in the severity of heart failure. In the study of Puri et al, patients had mild to moderately severe chronic heart failure (NYHA classes II and III) and a mean left ventricular ejection fraction (LVEF) of $33 \%$, whereas our patients, who were awaiting heart transplantation, had severe long standing heart failure (mean $\mathrm{LVEF}=12.8 \%$ ). In patients with mitral stenosis, $\mathrm{D}_{M}$ has been shown to decline progressively with increasing severity of the disease. ${ }^{20}$ In contrast, $\mathrm{V}_{\mathrm{C}}$ has a biphasic relation with disease severity. ${ }^{20}$ In mild to moderately severe mitral stenosis, $\mathrm{V}_{\mathrm{C}}$ is usually normal and may even be increased, whereas in severe cases it is reduced. ${ }^{21} 22$

MECHANISMS OF PULMONARY CAPILLARY BLOOD REDUCTION IN HEART TRANSPLANT CANDIDATES The volume of the pulmonary capillary blood at any instant $\left(\mathrm{V}_{\mathrm{C}}\right)$ depends on the number and dimensions of functioning pulmonary capillaries. ${ }^{21}$ The mechanisms by which the size of the pulmonary capillary bed is increased are not fully understood, but experimental and clinical studies suggest that this is caused by increases in pulmonary blood flow or pulmonary capillary transmural pressure, the transmural capillary pressure appearing to be more important than the pulmonary blood flow. ${ }^{23}$ These haemodynamic factors are believed to increase the size and uniformity of the pulmonary capillary bed by vascular recruitment and distension. ${ }^{23}$ Therefore in any condition in which pulmonary capillary transmural pressure or the pulmonary blood flow is increased (for example, exercise, congenital heart disease with left to right shunts, and the early stages of mitral stenosis and congestive heart failure), $V_{c}$ would be expected to be higher than normal. ${ }^{21}$ Under these circumstances, a normal or reduced $V_{C}$ would suggest derangement of the pulmonary vascular bed. ${ }^{21}$ The present study did not investigate the direct relation between $\mathrm{TL}_{\mathrm{CO}}$ components and pulmonary haemodynamics. However, previous reports on the relation of $\mathrm{TL}_{\mathrm{CO}}$ in general and $\mathrm{V}_{\mathrm{C}}$ in particular to pulmonary haemodynamics in patients with congenital and valvar heart diseases suggest an important role for the changes in pulmonary haemodynamics in heart transplant candidates. Congenital heart diseases which result in pulmonary vascular congestion and increased pulmonary blood flow without significant pulmonary arterial hypertension are associated with increased values of $\mathrm{TL}_{\mathrm{CO}}$ and its components, with $\mathrm{V}_{\mathrm{C}}$ increasing relatively more than $\mathrm{D}_{\mathrm{M}} \cdot{ }^{24}{ }^{25}$ However, if pulmonary arterial hypertension or pulmonary vascular resistance is severe, these variables are usually normal or reduced. ${ }^{24}$ Surgical correction of the congenital defects results in restoration of the pulmonary haemodynamics towards normal and this is associated with reduction in $\mathrm{TL}_{\mathrm{CO}}$ and its components. ${ }^{25} \mathrm{TL}_{\mathrm{CO}}$ in mitral valve disease has also been shown to be related to severity of pulmonary vascular resistance and pressures. ${ }^{22}$ In moderately severe mitral stenosis, the increase in pulmonary venous pressure would be expected to increase $\mathrm{V}_{\mathrm{C}}$ by expanding and increasing the uniformity of the pulmonary vascular bed. However, $\mathrm{V}_{\mathrm{C}}$ is usually normal or even reduced in these cases. ${ }^{20}$ This had been explained by an opposite force which counterbalances the augmenting effect of pulmonary congestion; namely, the obliteration of the pulmonary vascular bed by progressive fibrosis and repeated pulmonary emboli which are common in severe long standing mitral stenosis. $^{22} 26$

Like patients with mitral valve disease, $\mathrm{V}_{\mathrm{C}}$ in patients with severe chronic heart failure 
awaiting heart transplantation is determined by two factors acting in opposite directions, the increased pulmonary venous pressure tending to increase it and the pulmonary oedema and pulmonary hypertension and fibrosis tending to decrease it. Pulmonary hypertension, oedema and fibrosis will also lead to progressive decline in $\mathrm{D}_{M}$. The finding of equally reduced $\mathrm{D}_{M}$ and $\mathrm{V}_{C}$ in our heart transplant candidates is similar to the findings in patients with severe mitral stenosis, suggesting that these patients have significant pulmonary parenchymal and vascular abnormalities which may not be completely reversible after transplantation.

Cigarette smoking can reduce $\mathrm{TL}_{\mathrm{CO}}$ and its components by two mechanism, the first methodological and the second by causing lung damage. ${ }^{27}$ With respect to methodology, the effective driving pressure for gas transfer across the alveolar-capillary membrane is the difference between the alveolar partial pressure of the gas and its partial pressure in the pulmonary capillaries. ${ }^{16}$ In the measurement of $\mathrm{TL}_{\mathrm{CO}}$ and its components, the pulmonary capillary partial pressure of carbon monoxide is assumed to be zero. $^{16}$ In heavy smokers, the pulmonary capillary partial pressure for carbon monoxide and the carboxyhaemoglobin are increased, and this can lead to underestimation of $\mathrm{TL}_{\mathrm{CO}} \cdot{ }^{15}{ }^{16}$ Smoking related lung damage is exemplified by chronic obstructive pulmonary disease, which is often associated with $\mathrm{TL}_{\mathrm{CO}}$ reduction. Smoking has also been shown to reduce $\mathrm{TL}_{\mathrm{CO}}$ in asymptomatic subjects who had normal airway function, but this reduction was reversible within one year of smoking cessation. ${ }^{27}$ In our study, all subjects had normal airway function and all ex-smokers had stopped smoking for at least one year before assessment. In addition, there was no difference between candidates with a previous history of smoking and those without in any of the diffusion parameters. The history of previous smoking in our patients is therefore unlikely to have been a significant factor in the observed reduction in $\mathrm{TL}_{\mathrm{CO}}$ and its components.

In conclusion, $\mathrm{TL}_{\mathrm{CO}}$ reduction in patients with severe chronic heart failure awaiting heart transplantation is caused by a proportionate reduction in both its components $\left(\mathrm{D}_{\mathrm{M}}\right.$ and $\left.\mathrm{V}_{\mathrm{C}}\right)$, suggesting a significant disturbance of the pulmonary vascular bed.

1 Light RW, George RB. Serial pulmonary function in patients with acute heart failure. Arch Intern Med 1983;143:429-33.

2 Naum CC, Sciurba FC, Rogers RM. Pulmonary function abnormalities in chronic severe cardiomyopathy preceding cardiac transplantation. Am Rev Respir Dis 1992;145: cardiac
3 Bedell GN, Suzuki Y, Wilson WR. Pulmonary abnormalities in congestive heart failure. $\mathcal{F}$ Lab Clin Med 1961;58:798.

in congestive heart failure. $\mathcal{F}$ Lab Clin Med 1961;58:798.
Frand UI, Shim CS, Williams MH. Heroin-induced pulmonary edema: sequential studies of pulmonary function. Ann nary edema: sequential stucies

5 Siegel JL, Miller A, Brown LK, et al. Pulmonary diffusing capacity in left ventricular dysfunction. Chest 1990;98:5503.

6 Puri S, Baker BL, Oakley CM, et al. Increased alveolar/ capillary membrane resistance to gas transfer in patients with chronic heart failure. Br Heart f 1994;72:140-4.

7 Wright RS, Levine MS, Bellamy PE, et al. Ventilatory and diffusion abnormalities in potential heart transplant recipients. Chest 1990;98:816-20.

8 Groen HJ, Bogaard JM, Balk AH, et al. Diffusion capacity in heart transplant recipients. Chest 1992;102:456-60.

9 Niset G, Ninane V, Antoine $M$, et al. Respiratory dysfunction in congestive heart failure: correction after dysfunction in congestive heart failure: correction

10 Ravenscraft SA, Gross CR, Kubo SH, et al. Pulmonary function after successful heart transplantation. One year follow-up. Chest 1993;103:54-8.

11 Ohar J, Osterloh J, Ahmed N, et al. Diffusing capacity decreases after heart transplantation. Chest 1993;103:85761

12 Al-Rawas OA, Carter, Stevenson RD, et al. The time course of pulmonary transfer factor changes following heart transplantation. Eur $\mathcal{F}$ Cardiothorac Surg 1997;12:471-9.

13 Quanjer PH, Tammeling GJ, Cotes JE, et al. Lung volumes and forced ventilatory flows: official Statement of the European Respiratory Society. Eur Respir F. 1993;6:5-40.

14 Roughton FJW, Forster RE. Relative importance of diffusion and chemical reaction rates in determining rate of exchange of gases in the human lung, with special reference to true diffusing capaity of pulmonary membrane and volume of blood in the lung capillaries. $\mathcal{F}$ Appl Physiol 1957;11:290-302.

15 Cotes JE, Chinn DJ, Quanjer PH, et al. Standardisation of the measurement of transfer factor (diffusing capacity).
Report of Working Party-Standardisation of Lung Function Tests, European Community for Steel and Coal. Official Statement of the European Respiratory Society. Eur cial Statement of the European
Respir 7 Suppl 1993;16:41-52.

16 Cotes JE. Measurement of transfer factor (diffusing capacity and its subdivisions). In: Cotes JE, ed. Lung function: assessment and applications in medicine. Oxford: Blackwell Scientific Publications, 1993:299-324

17 American Thoracic Society. Lung function testing: selection of reference values and interpretative strategies. Am Rev Respir Dis 1991;144:1202-18.

18 Carter R, Al-Rawas OA, Stevenson RD, et al. The measurement of the single-breath transfer factor for carbon monoxide and its components using the Morgan Transflow system. Respir Med 1998;92:628-32.

19 Cotes JE. Lung function throughout life: determinants and reference values. In: Cotes JE, ed. Lung function: assessment reference values. In: Cotes JE, ed. Lung function: assessment and applications in medicine.

20 Gazioglu K, Yu PN. Pulmonary blood volume and pulmonary capillary blood volume in valvular heart disease. Circulation 1967;35:701-9.

21 Forster RE. Interpretation of measurements of pulmonary diffusing capacity. In: Fenn WO, Rahn H, eds. Handbook of physiology — section 3: Respiration. Washington, DC: American Physiological Society, 1965:1453-68.

22 Aber CP, Campbell JA. Significance of changes in the pulmonary diffusing capacity in mitral stenosis. Thorax 1965;20:135-45.

23 Forster RE. Diffusion of gases across the alveolar membrane. In: Farhi LE, Tenny SM, eds. Handbook of physiology. Bethesda: American Thoracic Society, 1987:7188.

24 Rankin J, Callies QC. Diffusing characteristics of the human lung in congenital and acquired heart disease. Circulation 1958;18:768.

25 Bucci G, Cook CD, Hamann JF. Studies of respiratory physiology in children. VI. Lung diffusing capacity, diffusng capacity of the pulmonary membrane and pulmonary capillary blood volume in congenital heart disease. $\mathcal{f}$ Clin Invest 1961;40:1431-41.

26 Forster RE, Ogilvie CM. The single-breath carbon monoxde transfer test 25 years on: a reappraisal. Thorax 1983;38: $1-9$.

27 Knudson RJ, Kaltenborn WT, Burrows B. The effects of cigarette smoking and smoking cessation on the carbon monoxide diffusing capacity of the lung in asymptomatic subjects. Am Rev Respir Dis 1989;140:645-51. 